\title{
Osteoporosis treatment in patients undergoing spinal fusion: a systematic review and meta-analysis
}

\author{
Vaidya Govindarajan, BS, Anthony Diaz, MS, Roberto J. Perez-Roman, MD, S. Shelby Burks, MD, \\ Michael Y. Wang, MD, and Allan D. Levi, MD, PhD
}

Department of Neurological Surgery and The Miami Project to Cure Paralysis, University of Miami Miller School of Medicine, Miami, Florida

\begin{abstract}
OBJECTIVE Bisphosphonates and teriparatide are the most common therapies used in the treatment of osteoporosis. Their impact on fusion rates in osteoporotic patients following spinal fusion has yet to be concretely defined, with previous systematic reviews focusing heavily on bisphosphonates and lacking clinical insight on the utility of teriparatide. Herein the authors present an updated meta-analysis of the utility of both bisphosphonates and teriparatide in improving spinal fusion outcomes in osteoporotic patients.
\end{abstract}

METHODS After a comprehensive search of the English-language literature in the PubMed and Embase databases, 11 clinical studies were included in the final qualitative and quantitative analyses. Of these studies, 9 investigated bisphosphonates, 7 investigated teriparatide, and 1 investigated a combination of teriparatide and denosumab. Odds ratios and 95\% confidence intervals were calculated where appropriate.

RESULTS A meta-analysis of the postoperative use of bisphosphonate demonstrated better odds of successful fusion as compared to that in controls during short-term monitoring (OR 3.33, 95\% Cl 1.72-6.42, $p=0.0003$ ) but not long-term monitoring $(p>0.05)$. Bisphosphonate use was also shown to significantly reduce the likelihood of postoperative vertebral compression fracture (VCF; OR 0.07, 95\% CI 0.01-0.59, $p=0.01$ ) and significantly reduce Oswestry Disability Index scores (mean difference $[\mathrm{MD}]=-2.19,95 \% \mathrm{Cl}-2.94$ to $-1.44, \mathrm{p}<0.00001)$ and visual analog scale pain scores $(\mathrm{MD}=$ $-0.58,95 \% \mathrm{Cl}-0.79$ to $-0.38, \mathrm{p}<0.00001$ ). Teriparatide was found to significantly increase fusion rates at long-term postoperative periods as compared to rates after bisphosphonate therapy, with patients who received postoperative teriparatide therapy 2.05 times more likely to experience successful fusion (OR 2.05, 95\% Cl 1.17-3.59, $p=0.01$ ).

CONCLUSIONS The authors demonstrate the benefits of bisphosphonate and teriparatide therapy independently in accelerating fusion during the first 6 months after spinal fusion surgery in osteoporotic patients. In addition, they show that teriparatide may have superior benefits in spinal fusion during long-term monitoring as compared to those with bisphosphonates. Bisphosphonates may be better suited in preventing VCFs postoperatively in addition to minimizing postoperative disability and pain.

https://thejns.org/doi/abs/10.3171/2021.3.FOCUS2175

KEYWORDS osteoporosis; spinal fusion; bisphosphonate; teriparatide; fracture; meta-analysis

$\mathrm{O}$ STEOPOROSIS is a common metabolic bone disease, affecting about 10.2 million US adults aged 50 years and older. ${ }^{1}$ Patients with osteoporosis have an increased risk of vertebral compression fractures (VCFs), occurring in approximately 550,000 osteoporotic patients each year. ${ }^{1-3}$ Osteoporosis occurs because of an imbalance between osteoclast activity, which is responsible for bone resorption, and osteoblast activity, leading to decreased bone mass. ${ }^{2}$ Osteoporosis is diagnosed when a World Health Organization T-score of -2.5 or lower is detected on a dual-energy x-ray absorptiometry (DEXA) scan. ${ }^{4}$ Furthermore, in patients requiring spinal fusion, osteoporosis may impair fusion because fusion is dependent on appropriate bone formation and remodeling. ${ }^{3}$ In addition to having lower fusion rates, patients are at an increased risk of cage subsidence, screw loosening, iatrogenic fractures, and proximal junctional kyphosis. ${ }^{5}$

Osteoporosis treatments may increase fusion rates in patients with lower bone mineral density (BMD) following spinal fusion. Among these therapies, bisphosphonates constitute the broadest and oldest class of drugs, suppressing bone resorption by binding to hydroxyapatite and pre-

ABBREVIATIONS BMD = bone mineral density; DEXA = dual-energy x-ray absorptiometry; MD = mean difference; ODI = Oswestry Disability Index; P1NP = amino-terminal propeptide of type 1 procollagen; RANKL = receptor activator of nuclear factor $\mathrm{K} B$ ligand; $\mathrm{VAS}=$ visual analog scale; $\mathrm{VCF}=$ vertebral compression fracture. SUBMITTED February 1, 2021. ACCEPTED March 19, 2021. INCLUDE WHEN CITING DOI: 10.3171/2021.3.FOCUS2175. 
venting its enzymatic cleavage. ${ }^{6}$ Anabolic agents are more modern medications, with teriparatide being the most widely studied. In contrast to bisphosphonates, teriparatide exerts its action by directly stimulating surface receptors in osteoblasts to amplify bone formation. ${ }^{7}$ The use of these treatments in osteoporotic patients has prompted investigation into their utility in the perioperative management of patients undergoing spinal fusion, with multiple animal studies having investigated both classes of drugs. ${ }^{5,8-12}$

Though clinical evidence supporting the use of osteoporosis therapies is expanding, there are few comprehensive meta-analyses investigating both bisphosphonates and teriparatide. While previous meta-analyses evaluating the impact of these agents on spinal fusion exist, these studies have focused heavily on the role of bisphosphonates. ${ }^{13-15}$ Furthermore, there have been very few recent systematic reviews detailing the impact of teriparatide on spinal fusion rates and none with meta-analyses of the available data. ${ }^{16}$ We present a comprehensive systematic review and meta-analysis of osteoporosis therapies and their impact on spinal fusion rates and offer novel findings on the utility of teriparatide in the postoperative treatment of osteoporotic patients who have undergone spinal fusion.

\section{Methods}

\section{Inclusion and Exclusion Criteria}

Studies evaluating clinical and radiological outcomes of spinal fusion in humans with osteoporosis were included in this review. The exclusion criteria were as follows: 1) studies with nonhuman cohorts; 2) studies that did not incorporate pharmacological management; 3) studies without a comparison or control group; 4) studies that did not evaluate spinal fusion outcomes; 5) studies that did not include a measurement of the fusion rate or a biomechanical, histological, radiographic, or microstructural assessment of fusion quality; 6) studies without a statistical analysis; and 7) case reports.

\section{Literature Search and Selection}

We performed a systematic search of the Englishlanguage literature dating from July 1990 to October 5, 2020, in the PubMed and Embase databases. The following medical subject heading $(\mathrm{MeSH})$ terms and free text words were used: "spinal fusion" or "arthrodesis" or "spine" or "osteoporosis" or "osteoporotic." A total of 247 published abstracts or papers were identified. As displayed in a PRISMA (Preferred Reporting Items for Systematic Reviews and Meta-Analyses) flowchart (Fig. 1), after applying the inclusion and exclusion criteria, a total of 11 papers were included in the qualitative analysis and 9 in the quantitative analysis. Selection and data extraction of the studies were independently performed by two authors (V.G. and A.D.).

\section{Data Analysis}

The pooled data analysis was performed with Review Manager 5.4 (RevMan, Cochrane). Odds ratios and 95\% confidence intervals were calculated using the MantelHaenszel test, and forest plots were generated for each comparison. Random-effects dichotomous models were developed to assess the overall effect of each drug in control and treatment groups. Our primary outcome of interest was fusion rate. Other secondary outcomes included VCF, postoperative screw loosening, postoperative BMD, postoperative Oswestry Disability Index (ODI), and postoperative visual analog scale (VAS) pain score. Risk of bias was assessed using the Cochrane risk-of-bias tool in order to give further insight into the conclusions made by us and our own subsequent meta-analyses.

\section{Results}

\section{Study Selection and Characteristics}

Eleven articles met the inclusion criteria from an initial pool of 247 articles. ${ }^{2,5,6,8-12,21,31,47}$ All studies had a controlled design and evaluated fusion mass radiographically, surgically, histologically, or a combination thereof. Nine studies were included in the quantitative analysis. ${ }^{2,5,6,10-12 \text {, }}$ ${ }_{21,31,47}$ Key differences are summarized in Table 1. Nine studies investigated bisphosphonates, 7 reviewed teriparatide, and 1 studied denosumab, a monoclonal receptor activator of nuclear factor $\kappa \mathrm{B}$ ligand (RANKL) antibody. Among the bisphosphonate studies, 5 used a negative control arm and the other 4 compared outcomes to a teriparatide treatment arm. Among the teriparatide studies, 2 had a negative control arm, 1 compared outcomes to a denosumab treatment arm, and the others compared outcomes to a bisphosphonate treatment arm. All studies evaluated fusion outcomes using CT and/or radiographs with dynamic views. All studies administered their interventions solely postoperatively except the study performed by Ide et al. (1 month preoperatively and 12 months postoperatively) and the studies performed by Ohtori et al. (treated 2 months prior in Ohtori et al., 2012 and 2013, and 3 months prior in Ohtori et al., 2015). ${ }^{8-11}$ The studies by Ohtori et al. also treated patients for 8 months, 10 months, and up to 10 months postoperatively in 2012,2013 , and 2015 , respectively. ${ }^{9-11}$

Characteristics of the intervention and control arms of the studies included in the quantitative analysis are summarized in Table 2. The numbers of intention-to-treat patients in the bisphosphonate, teriparatide, and control arms are also presented in Table 2. A risk-of-bias summary is presented in Fig. 2.

\section{Fusion Rates}

Fusion rates in most studies were reported as the number of fused index levels per total index levels assessed. Among the bisphosphonate versus negative control studies, 3 reported fusion rates at 6 months and 4 reported rates at 12 months postoperatively. Of the 102 levels that underwent fusion surgery in the bisphosphonate treatment arm and were evaluated for successful fusion at 6 months, $83(81.4 \%)$ met grade A or B fusion criteria based on the Bridwell system ${ }^{17}$ for either bilateral or unilateral bridging bone formation, respectively. In the control arm at 6 months, 65 (59.6\%) of 109 levels met fusion criteria. At 12 months, $105(85.4 \%)$ of 123 levels in the bisphosphonate treatment arm and $110(83.3 \%)$ of 132 levels in the control arm met fusion criteria. A Cochran-Mantel-Haenszel test demonstrated higher odds of successful fusion among 


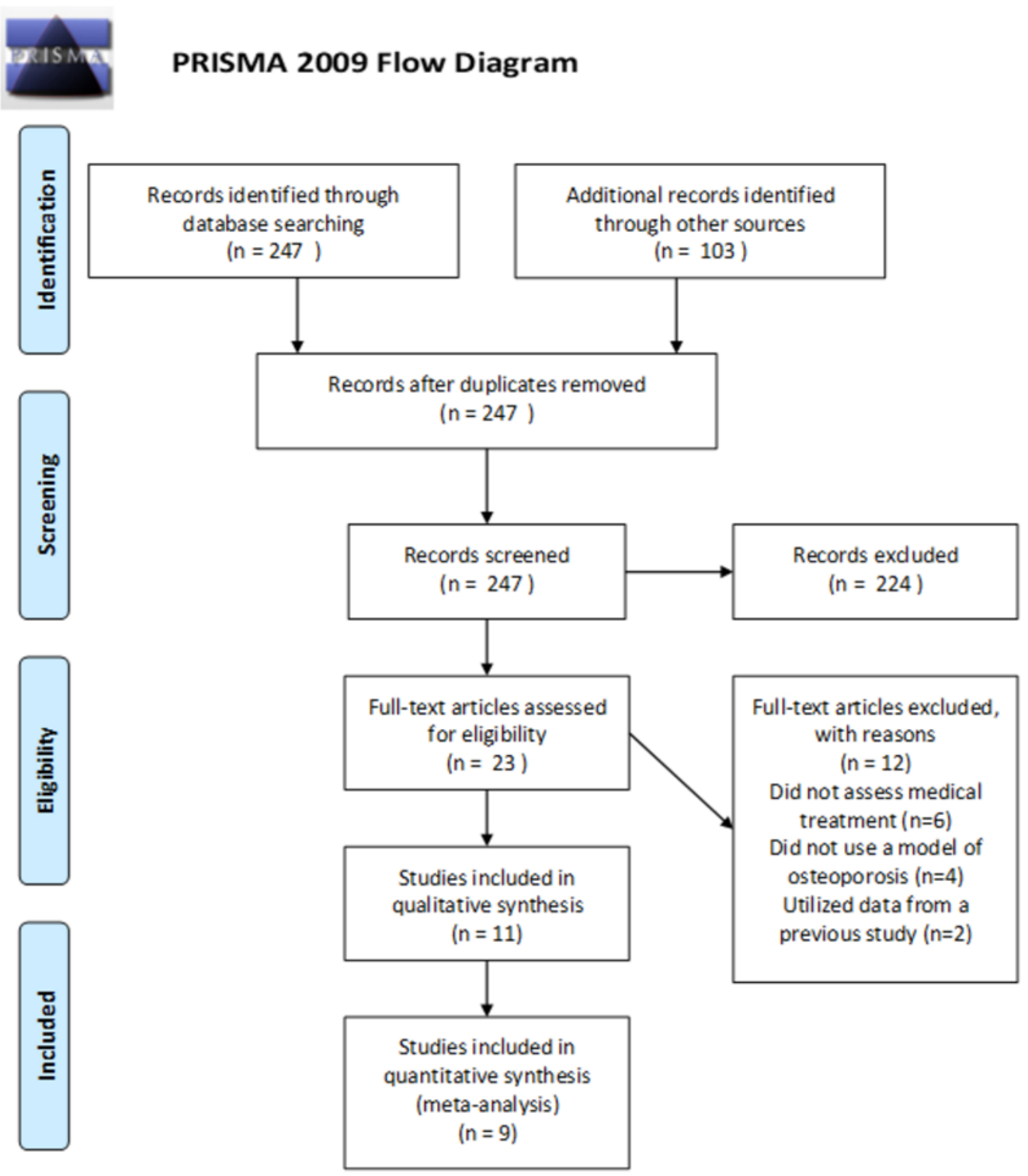

FIG. 1. Study flow diagram. Data added to the PRISMA template [from Moher D, Liberati A, Tetzlaff J, Altman DG, The PRISMA Group (2009). Preferred Reporting Items for Systematic Reviews and Meta-Analyses: The PRISMA Statement. PLoS Med 6(7): e1000097] under the terms of the Creative Commons Attribution License.

patients taking bisphosphonates versus unmedicated controls at 6 months postoperatively (OR 3.33, 95\% CI $1.72-$ $6.42, \mathrm{p}=0.0003$ ) but not at 12 months postoperatively (OR $1.14,95 \%$ CI $0.47-2.79, \mathrm{p}=0.77$; Fig. 3A and B). This suggests that bisphosphonate therapy might increase the rate of fusion only during the initial postoperative period $(\leq 6$ months) and not the long term.

Among the bisphosphonate versus teriparatide studies, 3 reported outcomes at 12 months and only 1 reported outcomes at 6 months. At 12 months, 122 (83.0\%) of 147 levels in the teriparatide treatment arm and $103(70.5 \%)$ of 146 levels in the bisphosphonate treatment arm met fusion criteria. When pooled, patients in the teriparatide treatment arm had significantly higher odds of success- ful fusion relative to bisphosphonate patients at 12 months (OR 2.05, 95\% CI 1.17-3.59, p = 0.01; Fig. 3C). Although meta-analysis was not possible for outcomes at 6 months, Cho et al. demonstrated higher fusion rates in teriparatide patients relative to those in bisphosphonate patients at 6 months. ${ }^{5}$ In a prospective study of 47 patients, they observed that $21(77.8 \%)$ of 27 levels in the teriparatide treatment arm and $15(53.6 \%)$ of 28 levels in the bisphosphonate treatment arm met fusion criteria.

Among the studies investigating teriparatide, only one compared fusion rates with a negative control. ${ }^{7}$ Among 75 osteoporotic patients who had undergone fusion surgery, those in the teriparatide group experienced significantly higher rates of bilateral bridging bone formation 
TABLE 1. Summary of studies, including primary endpoints, treatment duration, and follow-up duration

\begin{tabular}{|c|c|c|c|c|c|c|c|c|c|}
\hline $\begin{array}{l}\text { Authors } \\
\& \text { Year }\end{array}$ & $\begin{array}{l}\text { Study } \\
\text { Type }\end{array}$ & $\begin{array}{l}\text { No. of } \\
\text { Patients }\end{array}$ & $\begin{array}{l}\text { Age } \\
\text { (yrs) }\end{array}$ & T-Score & Procedure & Intervention & $\begin{array}{c}\text { Control } \\
\text { Arm }\end{array}$ & $\begin{array}{l}\text { Primary } \\
\text { Endpoint }\end{array}$ & $\begin{array}{l}\text { Treatment } \\
\quad \& \text { FU }\end{array}$ \\
\hline $\begin{array}{l}\text { Nagahama } \\
\text { et al., } 2011^{2}\end{array}$ & $\mathrm{RCT}$ & 40 & $>18$ & & 1-level PLIF & Alendronate & Vitamin D & Fusion rate & Wkly admin for 12 mos, 12 mos FU \\
\hline $\begin{array}{l}\text { Chen et al., } \\
2016^{21}\end{array}$ & $\mathrm{RCT}$ & 79 & $>18$ & $\leq-2.5$ & 1-level PLIF & Zoledronate & Saline & Fusion rate & Single infusion postop, 12 mos FU \\
\hline $\begin{array}{l}\text { Ebata et al., } \\
2017^{8}\end{array}$ & $\mathrm{RCT}$ & 74 & $>50$ & & $\begin{array}{l}\text { 1-level PLIF } \\
\text { or TLIF }\end{array}$ & Teriparatide & No medication & Fusion rate & Wkly admin for 6 mos, 6 mos FU \\
\hline $\begin{array}{l}\text { Ide et al., } \\
2018^{9}\end{array}$ & RCT & 16 & $74 \pm 7$ & & $\begin{array}{c}\text { 1-, 2-, or } \\
\text { 3-level PLIF }\end{array}$ & $\begin{array}{l}\text { Teriparatide \& } \\
\text { denosumab }\end{array}$ & Teriparatide & Fusion rate & Daily admin for 13 mos, 12 mos FU \\
\hline $\begin{array}{l}\text { Ohtori et al, } \\
2012^{10}\end{array}$ & Pros & 57 & $76.6 \pm 6.9$ & & $\begin{array}{l}\text { 1- or 2-level } \\
\text { PLF }\end{array}$ & Teriparatide & Risedronate & Fusion rate & Daily admin for 10 mos, 12 mos FU \\
\hline $\begin{array}{l}\text { Ohtori et al., } \\
2013^{11}\end{array}$ & Pros & 62 & $77.6 \pm 6.0$ & & $\begin{array}{l}\text { 1- or 2-level } \\
\text { PLF }\end{array}$ & $\begin{array}{l}\text { Teriparatide } \\
\text { or risedronate }\end{array}$ & No medication & $\begin{array}{c}\text { Screw } \\
\text { loosening }\end{array}$ & Daily admin for 12 mos, 12 mos FU \\
\hline $\begin{array}{l}\text { Cho et al., } \\
2017^{5}\end{array}$ & Pros & 47 & $>18$ & $<-2.5$ & $\begin{array}{l}\text { 1- or 2-level } \\
\quad \text { PLIF }\end{array}$ & Teriparatide & Alendronate & Fusion rate & $\begin{array}{l}\text { Treated at least } 12 \text { mos, } 24.7 \pm 2.0 \\
\text { mos FU (teriparatide, daily); } 29.9 \\
\pm 8.1 \text { mos FU (alendronate, wkly) }\end{array}$ \\
\hline $\begin{array}{l}\text { Kim et al., } \\
2014^{47}\end{array}$ & Retro & 44 & 64.7 & & 1-level LIF & Alendronate & No medication & Fusion rate & $\begin{array}{l}\text { Wkly admin until FU, mean } 33.8 \\
\text { mos FU }\end{array}$ \\
\hline $\begin{array}{l}\text { Ohtori et al., } \\
2015^{12}\end{array}$ & Retro & 45 & $71.0 \pm 7.0$ & & $\begin{array}{l}\text { 1- or 2-level } \\
\quad \text { PLF }\end{array}$ & Teriparatide & Risedronate & Fusion rate & $\begin{array}{l}\text { Daily teriparatide (5.5 or } 13 \text { mos) } \\
\text { or wkly risedronate ( } 13 \text { mos), } 18 \\
\text { mos FU }\end{array}$ \\
\hline $\begin{array}{l}\text { Ding et al., } \\
2017^{6}\end{array}$ & Retro & 64 & $>18$ & & $\begin{array}{l}\text { TLIF, unspeci- } \\
\text { fied levels }\end{array}$ & Zoledronate & No medication & Fusion rate & $\begin{array}{l}\text { Initial infusion then another after } \\
12 \text { mos, } 24 \text { mos FU }\end{array}$ \\
\hline $\begin{array}{l}\text { Kim et al., } \\
2018^{31}\end{array}$ & Retro & 84 & $>18$ & $<-2.5$ & $\begin{array}{l}\text { 1-, 2-, or 3- } \\
\text { level TLIF }\end{array}$ & Teriparatide & Risedronate & $\begin{array}{c}\text { Screw } \\
\text { loosening }\end{array}$ & $\begin{array}{l}\text { Daily teriparatide for } 6 \text { mos, then } 6 \\
\text { mos risedronate or wkly risedro- } \\
\text { nate for } 12 \text { mos, } 12 \text { mos FU }\end{array}$ \\
\hline
\end{tabular}

admin = administration; FU = follow-up; LIF = lumbar interbody fusion; PLF = posterior lumbar fusion; PLIF = posterior lumbar interbody fusion; Pros = prospective; RCT = randomized controlled trial; Retro = retrospective; TLIF = transforaminal lumbar interbody fusion; wkly = weekly.

Values are expressed as the mean \pm standard deviation, unless indicated otherwise.

relative to rates in controls at 6 months (69\% vs 35.1\%, $\mathrm{p}=0.013)$.

\section{VCF and Pedicle Screw Loosening}

While investigators were unable to demonstrate longterm differences in the fusion rate between bisphosphonates and control, several studies reported improvement in secondary outcomes. For example, Nagahama et al. and Chen et al. reported significantly lower rates of VCF in patients receiving risedronate treatment. ${ }^{2,21} \mathrm{~A}$ meta-analysis of these studies on the incidence of postoperative VCF demonstrated that patients receiving bisphosphonates were less likely to experience VCF than were patients who did not undergo bisphosphonate therapy (OR 0.07, 95\% CI $0.01-0.59, p=0.01$ ) as shown in Fig. 4C. Bisphosphonates have also been shown to limit cage subsidence and pedicle screw loosening. ${ }^{3,4}$

Several studies have also measured the efficacy of medical therapy in reducing screw loosening. Most studies have reported the screw loosening incidence as the number of patients with radiographic evidence regardless of the number of fusion levels. Two studies among those investigating bisphosphonates versus a negative control and 3 studies among those investigating teriparatide ver- sus bisphosphonate therapy reported screw loosening (Fig. $4 \mathrm{~A}$ and $\mathrm{B}$ ). No significant differences in the rate of screw loosening were observed between bisphosphonate therapy and negative controls (OR 0.35, 95\% CI 0.03-4.23, p = 0.41 ) or between teriparatide therapy and bisphosphonate therapy (OR 0.61, 95\% CI 0.27-1.37, $\mathrm{p}=0.23$ ).

\section{BMD}

BMD assessments at preoperative and postoperative time points were made in 2 studies that compared teriparatide versus bisphosphonate therapy (Fig. 5). BMD measurements in these studies were obtained from the femur neck using DEXA preoperatively and at the 1-year followup. No significant difference in BMD scores at the 1-year follow-up was observed between the two therapies (mean difference $[\mathrm{MD}]=0.24,95 \% \mathrm{CI}-0.02$ to $0.50, \mathrm{p}=0.07$ ).

\section{Clinical Outcomes: ODI and VAS}

The ODI and VAS scores were commonly reported scores for measuring clinical outcomes. Meta-analysis of mean ODI scores from 3 studies comparing bisphosphonate versus a negative control demonstrated that bisphosphonate therapy is significantly associated with a lower mean ODI score than that in controls (MD $=-2.19,95 \%$ 
TABLE 2. Characteristics of studies included in quantitative analyses

\begin{tabular}{|c|c|c|c|c|c|c|c|c|}
\hline \multirow[b]{2}{*}{$\begin{array}{l}\text { Authors } \\
\& \text { Year }\end{array}$} & \multicolumn{4}{|c|}{ Intervention Arm } & \multicolumn{4}{|c|}{ Control Arm } \\
\hline & $\begin{array}{c}\text { No. } \\
\text { of ITT } \\
\text { Patients }\end{array}$ & $\begin{array}{l}\text { No. } \\
\text { Receiving } \\
\text { Therapy* }\end{array}$ & $\begin{array}{l}\text { Mean Preop BMD } \\
\text { (femur neck/L1-4, } \\
\text { T-score, or \% YAM) }\end{array}$ & $\begin{array}{c}\text { Mean } \\
\text { Age (yrs) }\end{array}$ & $\begin{array}{c}\text { No. } \\
\text { of ITT } \\
\text { Patients }\end{array}$ & $\begin{array}{l}\text { No. } \\
\text { Receiving } \\
\text { Therapy* }\end{array}$ & $\begin{array}{l}\text { Mean Preop BMD } \\
\text { (femur neck/L1-4, } \\
\text { T-score, or \% YAM) }\end{array}$ & $\begin{array}{c}\text { Mean } \\
\text { Age (yrs) }\end{array}$ \\
\hline $\begin{array}{l}\text { Nagahama } \\
\text { et al., } 2011^{2}\end{array}$ & 20 & 19 & -2.6 & 70.2 & 20 & 17 & -1.9 & 67.4 \\
\hline $\begin{array}{l}\text { Chen et al., } \\
2016^{21}\end{array}$ & 40 & 33 & $0.485 \pm 0.005 / 0.709 \pm 0.003$ & $65 \pm 8$ & 39 & 36 & $0.483 \pm 0.005 / 0.698 \pm 0.004$ & $63 \pm 7$ \\
\hline $\begin{array}{l}\text { Ohtori et } \\
\text { al., } 2012^{10}\end{array}$ & 29 & 29 & $65 \pm 5$ & $76 \pm 6.5$ & 28 & 28 & $64 \pm 6$ & $77 \pm 6.0$ \\
\hline $\begin{array}{l}\text { Ohtori et } \\
\text { al., } 2013^{11}\end{array}$ & 40 & 40 & $\begin{array}{l}66 \pm 4 \text { (teriparatide) } \\
64 \pm 4 \text { (risedronate) }\end{array}$ & $\begin{array}{c}78 \pm 6.0 \\
\text { (teriparatide), } \\
75 \pm 5.0 \\
\text { (risedronate) }\end{array}$ & 22 & 22 & $64 \pm 6$ & $77 \pm 5.8$ \\
\hline $\begin{array}{l}\text { Cho et al., } \\
2017^{5}\end{array}$ & 23 & 23 & $-3.7 \pm 0.6$ & $71.0 \pm 4.9$ & 24 & 24 & $-3.5 \pm 0.6$ & $68.2 \pm 8.4$ \\
\hline $\begin{array}{l}\text { Kim et al., } \\
2014^{47}\end{array}$ & 21 & 21 & -3.75 & NA & 23 & 23 & -3.98 & NA \\
\hline $\begin{array}{l}\text { Ohtori et } \\
\text { al., } 2015^{12}\end{array}$ & 30 & 30 & $\begin{array}{c}65.6 \pm 6 \text { (long) } \\
63.0 \pm 7.8 \text { (short) }\end{array}$ & $\begin{array}{l}72 \pm 7.7 \text { (long) } \\
69 \pm 7.1 \text { (short) }\end{array}$ & 15 & 15 & $66.8 \pm 8.0$ & $71 \pm 6.0$ \\
\hline $\begin{array}{l}\text { Ding et al., } \\
2017^{6}\end{array}$ & 30 & 30 & NA & $64.53 \pm 6.86$ & 34 & 34 & NA & $66.44 \pm 6.44$ \\
\hline $\begin{array}{l}\text { Kim et al., } \\
2018^{31}\end{array}$ & 33 & 33 & $-3.09 \pm 0.49$ & $69.48 \pm 7.76$ & 51 & 51 & $-2.94 \pm 0.39$ & $66.75 \pm 6.46$ \\
\hline
\end{tabular}

ITT = intention to treat; long = long duration; NA = not available; short = short duration; YAM = young adult mean.

Values are expressed as the mean \pm standard deviation, unless indicated otherwise.

CI -2.94 to $-1.44, \mathrm{p}<0.00001$; Fig. 6A). When teriparatide therapy was compared to bisphosphonate therapy, teriparatide patients demonstrated a nonsignificant decrease in ODI scores ( $\mathrm{MD}=-1.74,95 \% \mathrm{CI}-3.74$ to $0.27, \mathrm{p}=0.09$; Fig. 6B). Mean VAS scores were also significantly lower in the bisphosphonate therapy group relative to those in negative controls $(\mathrm{MD}=-0.58,95 \% \mathrm{CI}-0.79$ to $-0.38, \mathrm{p}$ $<0.00001$; Fig. 6C). In contrast to ODI scores, VAS scores were significantly lower among patients taking teriparatide therapy than among those in the bisphosphonate arm $(\mathrm{MD}=-0.35,95 \% \mathrm{CI}-0.64$ to $-0.05, \mathrm{p}=0.02$; Fig. 6D).

\section{Metabolic Markers}

In a retrospective study exploring fusion outcomes with zoledronate, Ding et al. measured the bone metabolic markers carboxy-terminal cross-linked telopeptide of type I collagen ( $\beta$-CTX) and amino-terminal propeptide of type 1 procollagen (P1NP) at 10 days and at 3-month intervals up to 12 months postoperatively. ${ }^{6}$ Both markers were significantly suppressed in the zoledronate group at all time points $(\mathrm{p}<0.05)$, which indicates decreased bone resorption. Ebata et al., in a randomized controlled trial assessing fusion outcomes with teriparatide therapy, also measured the serum concentrations of P1NP and tartrateresistant acid phosphatase 5b (TRACP-5b) as biomarkers of bone formation and bone resorption, respectively. ${ }^{8}$ At 1 month postoperatively, patients in the teriparatide arm had a significantly higher serum concentration of P1NP $(\mathrm{p}<0.012)$ and a significantly lower serum concentration of TRACP-5b at 6 months $(\mathrm{p}<0.001)$. The authors also measured serum concentrations of alkaline phosphatase, a marker of bone formation, in their patient cohort. In the patients who received teriparatide alone, serum alkaline phosphatase concentrations were significantly higher 3 months postoperatively $(\mathrm{p}<0.05)$.

\section{Discussion}

The increasing prevalence of osteoporosis and spine procedures has prompted interest in the utility of adjuvant medications in improving successful postoperative fusion. Currently, the two most prevalent treatment classes for decreased BMD are bisphosphonates, which inhibit the enzymatic cleavage of hydroxyapatite, and teriparatide, which directly stimulates osteoblasts to augment bone formation. ${ }^{14,15}$ However, the current level of evidence regarding the utility of these drug classes remains unclear, with the most recent systematic reviews on the subject lacking objective assessment of these agents' utility. ${ }^{16,18,19}$ In addition, short-term versus long-term effects of these medical therapies on fusion remain unclear.

\section{Fusion Rates}

Nine studies explored fusion rates in osteoporotic patients treated with medical therapy. Five of these compared bisphosphonate outcomes to negative controls, ${ }^{2,6,13,20,21} 1$ compared teriparatide to negative controls, ${ }^{8}$ and 3 compared teriparatide to bisphosphonates..$^{5,10,12}$ 


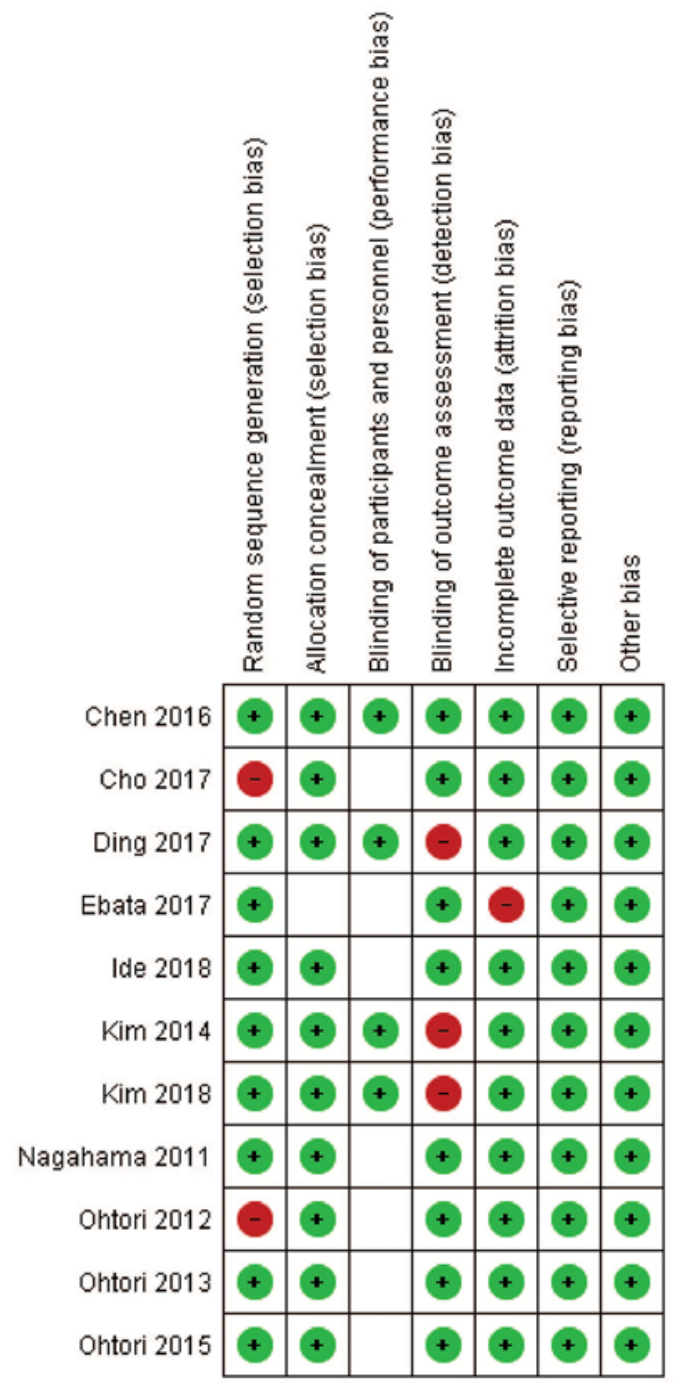

FIG. 2. Risk-of-bias summary for included studies. Green plus denotes low risk of bias. Red minus denotes high risk of bias. Empty cell denotes unclear risk.

The use of bisphosphonates in patients undergoing spinal fusion surgery has been a source of debate. Prior animal studies have demonstrated that bisphosphonates may negatively modulate spinal fusion by inhibiting osteoclast activity and, subsequently, bone remodeling. ${ }^{22-25}$ In a prospective study comparing bone fusion rates in patients taking long-term bisphosphonates ( $\geq 2$ years) and nonusers, Kang et al. found that long-term bisphosphonate users had significant delayed union 6 months after fusion relative to that in nonusers ( $26 \%$ vs $42 \%$, respectively; $\mathrm{p}<0.05){ }^{26}$ At the long-term follow-up, however, no significant differences in fusion rates were observed. The authors postulated that bisphosphonates delay bone callus maturation rather than inhibit fusion, which may explain the delay in fusion seen in the alendronate group. Conversely, in a retrospective review of patients who received a single dose of zoledronate after posterolateral fusion, Park et al. demonstrated no significant decrease in fusion mass in patients who had received zoledronate. ${ }^{27}$
In all studies that explored the effects of bisphosphonate therapy on lumbar spinal fusion rates in patients with osteoporosis at 6 months or less, bisphosphonates accelerated the fusion process. ${ }^{2,6,21}$ At 12 months, these differences were nonsignificant. Our group analyses confirmed these observations by demonstrating higher odds of successful fusion at 6 months (OR 3.33, $\mathrm{p}=0.0003)$ but not at 12 months (OR 1.14, $\mathrm{p}=0.77$ ).

In contrast to bisphosphonates, teriparatide administration has enhanced spinal fusion in various animal models. ${ }^{28-30}$ In a multicenter, prospective randomized controlled trial, Ebata et al. explored the role of once-weekly teriparatide therapy in osteoporotic women after fusion surgery. ${ }^{8}$ They observed that teriparatide treatment significantly enhanced rates of complete fusion at 6 months relative to rates in the control arm (69\% vs 35\%, $\mathrm{p}=0.013)$. To our knowledge, long-term studies exploring fusion rates at 12 months in patients taking teriparatide versus negative controls have not been reported.

With both teriparatide and bisphosphonates having clear benefits in enhancing spinal fusion during the shortterm postoperative period and a clear difference in the cost of treatment, determining differences in outcomes is important. All 3 studies that explored fusion rates between teriparatide and bisphosphonates demonstrated significantly higher rates of complete spinal fusion in the long term among the teriparatide-treated patients. ${ }^{5,10,12}$ This finding was confirmed in our group analysis, which demonstrated an OR of 2.05 ( $p=0.01)$ for successful fusion in favor of teriparatide. Cho et al. also demonstrated a superior rate of complete fusion at 6 months in the teriparatide group ( $78 \%$ vs $54 \%$ ).

Lastly, supplementation of teriparatide with denosumab may also improve fusion rates. In a randomized controlled trial investigating the daily use of $20 \mu \mathrm{g}$ of subcutaneous teriparatide therapy alone versus supplementation with $60 \mathrm{mg}$ of denosumab every 6 months after fusion, Ide et al. demonstrated bone union rates of $82 \%$ and $91 \%$ at 6 and 12 months, respectively, in the combination therapy arm versus $36 \%$ and $64 \%$ in the teriparatide-alone arm. ${ }^{9}$ In addition, teriparatide's potent anabolic effects on bone remodeling and ability to preferentially activate osteoblasts has shown a significantly higher degree of improvement in BMD long-term ( $\geq 12$ months) relative to that with bisphosphonates. ${ }^{5,9,31}$

\section{Bone Quality}

Regarding the role of bisphosphonates in increasing bone quality, multiple studies have demonstrated the ability of bisphosphonates to prevent VCFs and screw loosening. ${ }^{32,33}$ In a prospective randomized controlled trial with 2027 women with osteoporosis and preexisting vertebral fractures, Black et al. demonstrated a significant reduction in subsequent VCFs among patients in the alendronate group (8\%) relative to those in the control group $(15 \%) .{ }^{34}$ Our meta-analysis confirms this finding as well. Therefore, although bisphosphonates may not be the optimal therapy for augmenting fusion rates, they may have a role in preventing pathological changes, such as VCFs, and reducing postoperative pain and disability in osteoporotic patients undergoing spinal fusion., ${ }^{2,6,21}$ Currently, 


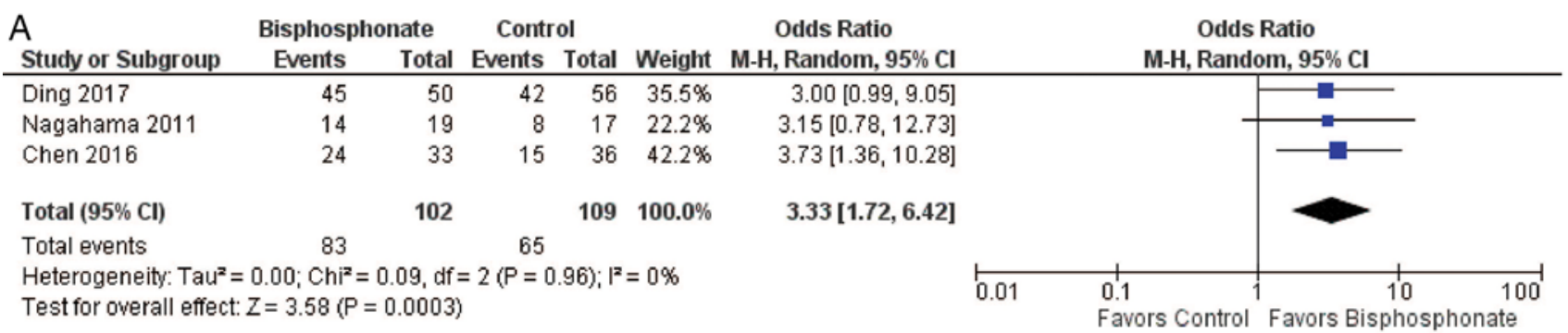

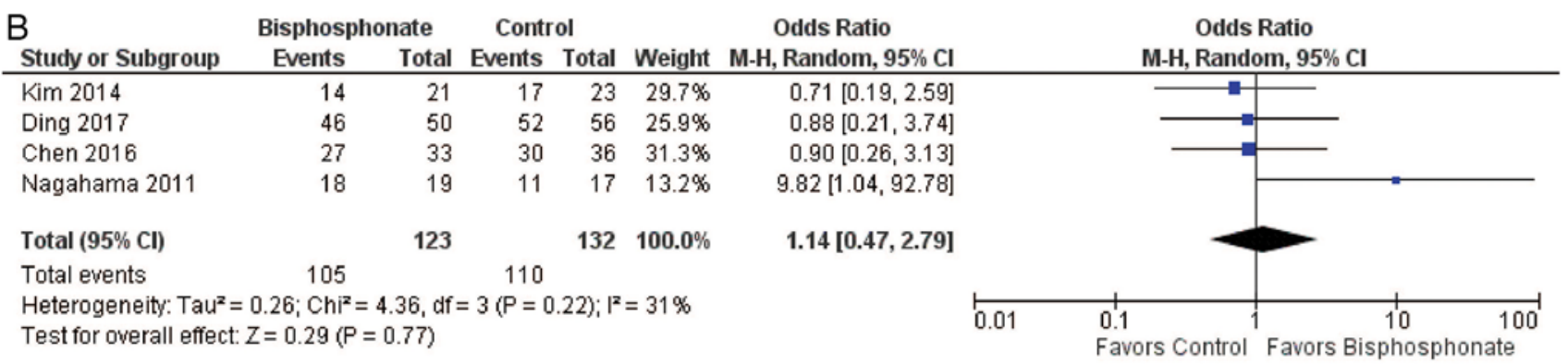

\begin{tabular}{|c|c|c|c|c|c|}
\hline \multirow{2}{*}{$\begin{array}{l}\text { C } \\
\text { Study or Subgroup }\end{array}$} & \multicolumn{2}{|c|}{ Teriparatide } & \multicolumn{2}{|c|}{ Bisphosphonate } & \multirow[b]{2}{*}{ Weight } \\
\hline & Events & Total & Events & Total & \\
\hline Ohtori 2012 & 62 & 78 & 53 & 78 & $59.8 \%$ \\
\hline Cho 2017 & 24 & 27 & 22 & 28 & $14.0 \%$ \\
\hline Ohtori 2015 & 36 & 42 & 28 & 40 & $26.2 \%$ \\
\hline Total $(95 \% \mathrm{Cl})$ & & 147 & & 146 & $100.0 \%$ \\
\hline Total events & 122 & & 103 & & \\
\hline $\begin{array}{l}\text { Heterogeneity: Tau }{ }^{z} \\
\text { Test for overall effec }\end{array}$ & $\begin{array}{l}00 ; \mathrm{Ch} \\
=2.50\end{array}$ & $\begin{array}{l}0.27 \\
0.0\end{array}$ & 1) & & \\
\hline
\end{tabular}

Odds Ratio

Random, $95 \% \mathrm{Cl}$

Odds Ratio

$1.83[0.88,3.78]$

$2.18[0.49,9.80]$

$2.57[0.86,7.70]$

$2.05[1.17,3.59]$

Test for overall effect: $Z=2.50(P=0.01)$

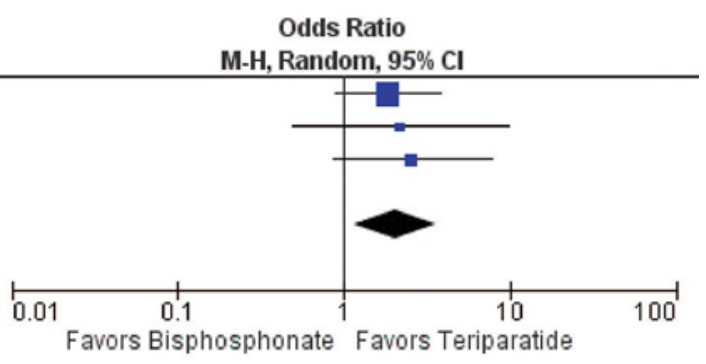

FIG. 3. Impact of medical therapy on fusion rates at $6(A)$ and 12 (B and $C$ ) months postoperatively. A: Patients undergoing postoperative bisphosphonate therapy were 3.33 times more likely to experience successful fusion at 6 months relative to patients who did not receive postoperative bisphosphonate treatment (OR 3.33, 95\% $\mathrm{Cl} 1.72-6.42, p=0.0003$ ). B: Patients undergoing postoperative bisphosphonate therapy did not experience any difference in fusion rates at 12 months postoperatively as compared to patients without bisphosphonate treatment $(\mathrm{OR} 1.14,95 \% \mathrm{Cl} 0.47-2.79, \mathrm{p}=0.77)$. C: Patients receiving postoperative teriparatide therapy were 2.05 times more likely to experience successful fusion relative to patients who received postoperative bisphosphonate therapy (OR 2.05, 95\% Cl 1.17-3.59, $\mathrm{p}=0.01)$.

animal models have demonstrated that zoledronate and teriparatide synergistically accelerate fusion mass and bone deposition. ${ }^{35}$

Denosumab, a monoclonal antibody that has been used as a fracture prophylactic in postmenopausal osteoporotic females, is another potential therapy. ${ }^{19}$ It exerts its protective effects by binding to and inactivating RANKL. ${ }^{9}$ RANKL has been demonstrated to increase osteoclast proliferation and activity, and the reduction of estrogen in older females has been shown to increase tissue exposure to RANKL, stimulating bone resorption. ${ }^{36}$ Two long-term randomized controlled clinical trials (Fracture Reduction Evaluation of Denosumab in Osteoporosis Every 6 Months [FREEDOM]) have shown that denosumab significantly reduces bone turnover markers, reduces fracture rates, and demonstrates low rates of adverse events. ${ }^{37,38}$ More studies investigating the impact of denosumab following spinal fusion are necessary to determine its clinical value and structural impact.

In contrast to bisphosphonates and denosumab, teriparatide has demonstrated anabolic effects by directly accelerating bone formation and fracture healing in multiple clinical studies, including in vertebral fractures. ${ }^{39-41}$ Furthermore, teriparatide has been shown to be effective in short-term administrations, with fusion mass acceleration being demonstrated with treatment durations as short as 8 weeks..$^{13,42,43}$ However, the results of our meta-analyses demonstrate that teriparatide has limited benefit in improving secondary outcomes such as postoperative pain and disability. Larger prospective trials are still needed to elucidate the true effect on clinical outcomes.

\section{Clinical Outcomes}

Clinical outcomes, as measured by ODI and VAS scores, were better in nearly all therapy groups relative to those in controls. When ODI and VAS scores were pooled, we observed that the bisphosphonate treatment was significantly associated with lower mean ODI and VAS scores relative to those in negative controls. This was in contrast to scores in the teriparatide group compared to those in a negative control group among the 3 studies included in our review. ${ }^{7,8,11}$ Although teriparatide is known to reduce back pain ${ }^{44}$ no differences in pain or ODI scores were observed 


\begin{tabular}{|c|c|c|c|c|c|c|c|c|c|}
\hline $\begin{array}{l}\text { A } \\
\text { Study or Subgroup }\end{array}$ & $\begin{array}{c}\text { Bisphosp } \\
\text { Events }\end{array}$ & $\begin{array}{l}\text { nate } \\
\text { Total }\end{array}$ & $\begin{array}{l}\text { Contı } \\
\text { Events }\end{array}$ & $\begin{array}{l}\text { ol } \\
\text { Total }\end{array}$ & Weight & $\begin{array}{c}\text { Odds Ratio } \\
\text { M-H, Random, 95\% Cl }\end{array}$ & $\begin{array}{r}\text { Odds } \\
\text { M-H, Rand }\end{array}$ & $\begin{array}{l}\text { Ratio } \\
\text { lom, } 95 \% \mathrm{Cl}\end{array}$ & \\
\hline Ding 2017 & 0 & 30 & 6 & 34 & $37.6 \%$ & $0.07[0.00,1.33]$ & 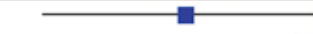 & & \\
\hline Ohtori 2013 & 5 & 20 & 6 & 22 & $62.4 \%$ & $0.89[0.22,3.53]$ & & & \\
\hline Total $(95 \% \mathrm{Cl})$ & & 50 & & 56 & $100.0 \%$ & $0.35[0.03,4.23]$ & & & \\
\hline Total events & 5 & & 12 & & & & & & \\
\hline $\begin{array}{l}\text { Heterogeneity: Tau } \\
\text { Test for overall effec }\end{array}$ & $\begin{array}{l}2.13 ; \mathrm{Chi}^{2} \\
Z=0.83(\mathrm{P}\end{array}$ & $\begin{array}{l}\text { 56, } d f= \\
41)\end{array}$ & $1(P=0$ & $.11) ; 1^{2}$ & $=61 \%$ & & $\begin{array}{cc}0.002 & 0.1 \\
\text { Favors } & \text { Bisphosphonate }\end{array}$ & $1 \frac{10}{\text { Favors Control }}$ & 500 \\
\hline
\end{tabular}

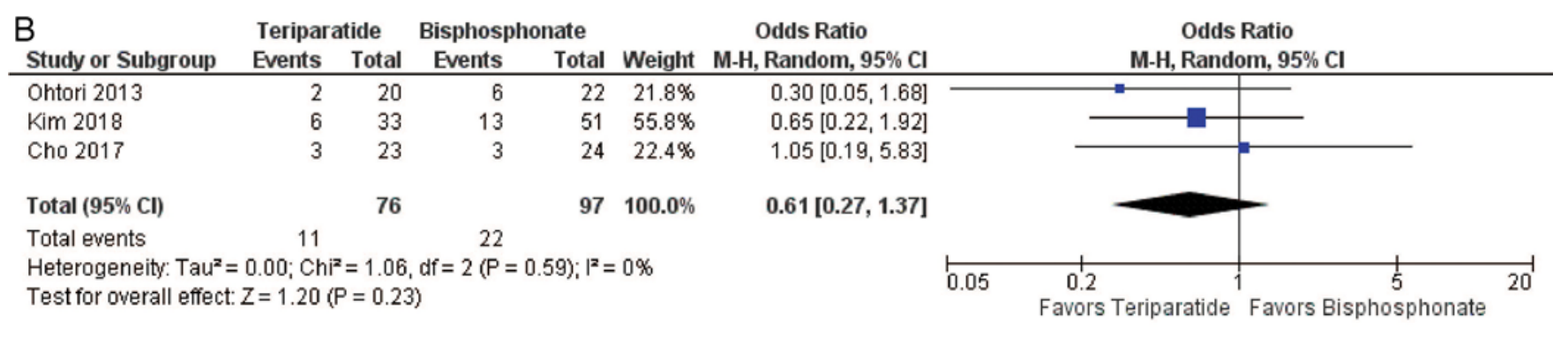

\begin{tabular}{|c|c|c|c|c|c|c|c|c|c|}
\hline $\mathrm{C}_{\text {Study or Subgroup }}$ & Bisphos! & late & Cont & ol & Weight & $\begin{array}{c}\text { Odds Ratio } \\
\text {. }\end{array}$ & $\begin{array}{r}\text { Odds } \\
\text { My Rand }\end{array}$ & S Ratio & \\
\hline Chen 2016 & 0 & 33 & 6 & 36 & $51.4 \%$ & $0.07[0.00,1.30]$ & 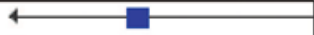 & & \\
\hline Nagahama 2011 & 0 & 19 & 4 & 17 & $48.6 \%$ & $0.08[0.00,1.55]$ & & & \\
\hline Total $(95 \% \mathrm{Cl})$ & & 52 & & 53 & $100.0 \%$ & $0.07[0.01,0.59]$ & & & \\
\hline Total events & 0 & & 10 & & & & & & \\
\hline $\begin{array}{l}\text { Heterogeneity: Tau= } \\
\text { Test for overall effec }\end{array}$ & $\begin{array}{l}0.00 ; \mathrm{Chi}^{2} \\
\mathrm{Z}=2.45(\mathrm{~F}\end{array}$ & $\begin{array}{l}00, \mathrm{df} \\
.01)\end{array}$ & $=1(P=$ & $96) ; 1^{2}$ & $=0 \%$ & & $\begin{array}{ll}0.01 & 0.1 \\
\text { Favors } & \text { Bisphosphonate }\end{array}$ & $\begin{array}{l}10 \\
\text { Favors Control }\end{array}$ & 100 \\
\hline
\end{tabular}

FIG. 4. Impact of medical therapy on postoperative screw loosening. A: No significant differences in rates of cases with screw loosening among patients receiving postoperative bisphosphonate versus controls (OR 0.35, 95\% $\mathrm{Cl} 0.03-4.23, p=0.41)$. B: No significant differences in rates of cases with screw loosening between teriparatide and bisphosphonates was detected (OR 0.61, $95 \% \mathrm{Cl} 0.27-1.37, p=0.23)$. C: Summary of bisphosphonates' impact on rates of postoperative VCF. Patients who received postoperative bisphosphonate therapy demonstrated significantly lower rates of postoperative VCF than the patients who did not receive postoperative bisphosphonate therapy (OR $0.07,95 \% \mathrm{Cl} 0.01-0.59, \mathrm{p}=0.01)$.

between teriparatide and controls. Similarly, in the studies that compared teriparatide therapy with bisphosphonates as a control, no statistical difference in ODI scores between the two groups was observed..$^{10,11,31}$ However, mean VAS scores were significantly lower in the teriparatide group.

The results of our meta-analysis suggest that postoperative teriparatide treatment may be beneficial in accelerating and promoting fusion in osteoporotic patients. Likewise, our findings suggest that teriparatide is superior to bisphosphonates in increasing fusion rates and is associated with lower postoperative VAS scores in osteoporotic patients. However, more studies comparing patients who received postoperative teriparatide to unmedicated patients are necessary. On the basis of our analysis, we believe that teriparatide offers a superior option for rapid and complete spinal fusion relative to bisphosphonates and suggest that teriparatide be utilized immediately after surgery barring any contraindications.

Lastly, it is well known that teriparatide is costly and that some insurance companies may not cover its cost. Although a cost-benefit analysis has not been previously reported, we believe that the elevated cost of teriparatide is offset by the significantly higher rates of complete fusion associated with its use. Lower rates of fusion may expose patients to

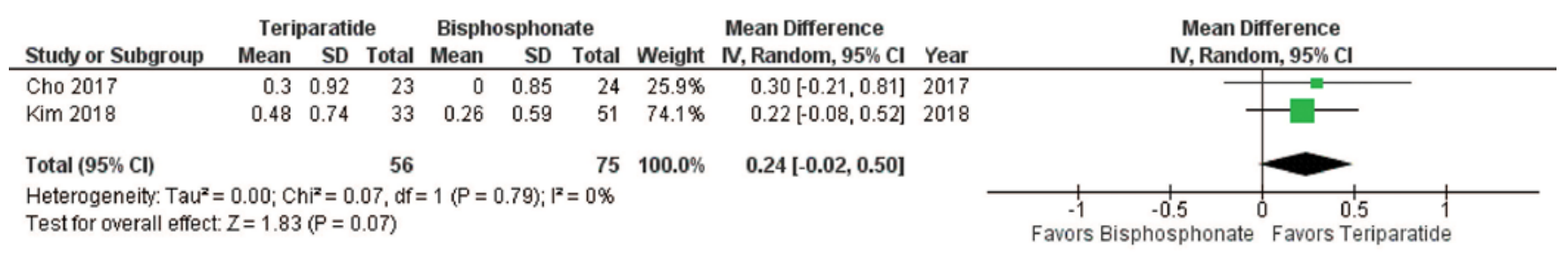

FIG. 5. Impact of postoperative medical therapy on BMD in osteoporotic patients who underwent spinal fusion. No significant difference in mean BMD T-scores was observed between teriparatide and bisphosphonate therapy $(\mathrm{MD}=0.24,95 \% \mathrm{Cl}-0.02$ to $0.50, p=0.07)$. 


\begin{tabular}{|c|c|c|c|c|c|c|c|c|c|c|c|}
\hline \multirow{2}{*}{$\begin{array}{l}\text { A } \\
\text { Study or Subgroup }\end{array}$} & \multicolumn{3}{|c|}{ Bisphosphonate } & \multicolumn{3}{|c|}{ Control } & \multirow{3}{*}{$\frac{\text { Weight }}{1.5 \%}$} & \multirow{2}{*}{$\begin{array}{l}\text { Mean Difference } \\
\text { IV, Random, } 95 \% \mathrm{Cl}\end{array}$} & \multirow{2}{*}{\multicolumn{3}{|c|}{$\begin{array}{l}\text { Mean Difference } \\
\text { IV, Random, } 95 \% \mathrm{Cl}\end{array}$}} \\
\hline & Mean & SD & Total & Mean & SD & Total & & & & & \\
\hline Nagahama 2011 & 9.315 & 8.52 & 19 & 14.65 & 9.89 & 17 & & $-5.34[-11.40,0.73]$ & 4 & - & \\
\hline Ding 2017 & 17.63 & 1.377 & 30 & 19.82 & 1.766 & 34 & $94.7 \%$ & $-2.19[-2.96,-1.42]$ & & & \\
\hline Ohtori 2013 & 21 & 8 & 20 & 22 & 4 & 22 & $3.7 \%$ & $-1.00[-4.88,2.88]$ & & & \\
\hline Total $(95 \% \mathrm{Cl})$ & & & 69 & & & 73 & $100.0 \%$ & $-2.19[-2.94,-1.44]$ & & & \\
\hline \multicolumn{7}{|c|}{$\begin{array}{l}\text { Heterogeneity: } \mathrm{Tau}^{2}=0.00 ; \mathrm{Chi}^{2}=1.39, \mathrm{df}=2(\mathrm{P}=0.50) ; I^{2}=0 \% \\
\text { Test for overall effect: } Z=5.73(P<0.00001)\end{array}$} & & & $\begin{array}{l}-10 \\
\text { Favors Bisphosphonate }\end{array}$ & Favors & $\begin{array}{c}5 \\
5 \\
\text { ntrol }\end{array}$ \\
\hline
\end{tabular}

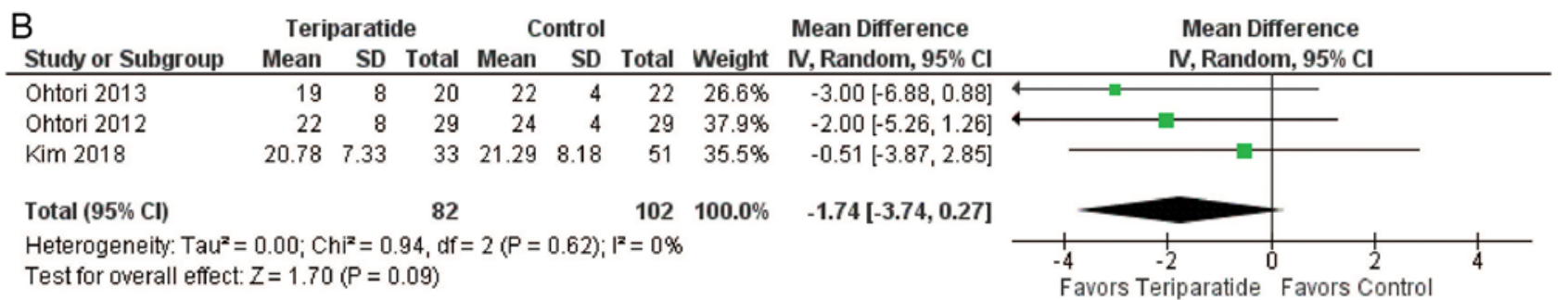

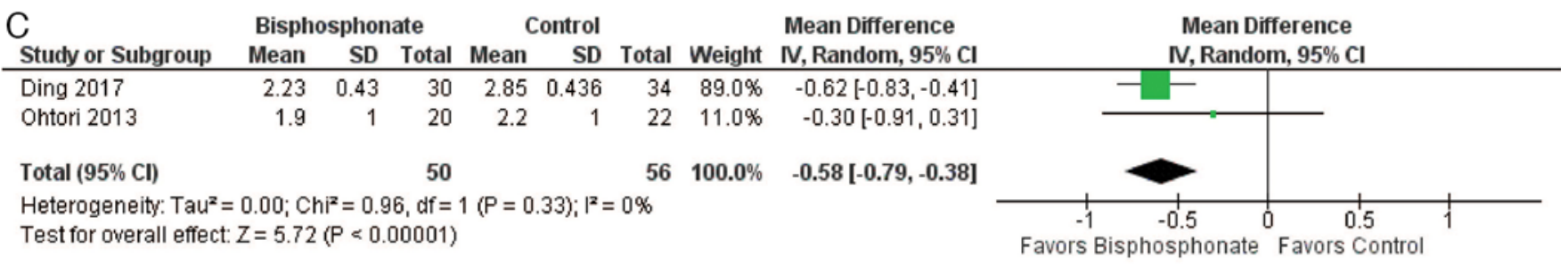

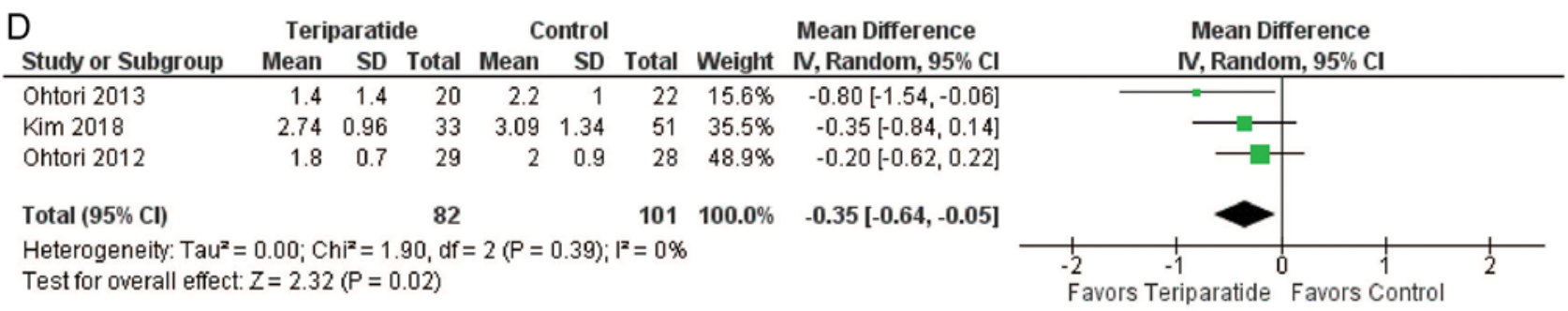

FIG. 6. Impact of medical therapy on ODI and VAS scores. A: Patients undergoing postoperative bisphosphonate therapy had significantly lower ODI scores following bisphosphonate therapy (MD $=-2.19,95 \% \mathrm{Cl}-2.94$ to $-1.44, \mathrm{p}<0.00001)$. B: Patients undergoing postoperative teriparatide therapy did not experience significantly lower ODI scores relative to those in patients who did not undergo postoperative teriparatide therapy $(\mathrm{MD}=-1.74,95 \% \mathrm{Cl}-3.74$ to $0.27, \mathrm{p}=0.09)$. C: Patients undergoing postoperative bisphosphonate therapy had significantly lower VAS scores (MD $=-0.58,95 \% \mathrm{Cl}-0.79$ to $-0.38, \mathrm{p}<0.00001)$. D: Patients undergoing postoperative teriparatide therapy had significantly lower VAS scores (MD $=-0.35,95 \% \mathrm{Cl}-0.64$ to $-0.05, p=0.02$ ).

pathological fractures or revision surgery for pseudarthrosis, thus increasing long-term costs and morbidity. ${ }^{45,46}$ Physicians should assess which patients require a more aggressive course of biologics preoperatively (e.g., patients with more severe pathology based on a history of prior fracture and/or BMD scores) and the patient's insurance provider and prescribe treatment accordingly. Also, the assessment for teriparatide candidacy should begin prior to surgery, as the insurance approval process may be lengthy.

There may also be benefits to preoperative treatment with teriparatide, as shown by Ohtori and colleagues..$^{10-12}$ However, without a direct comparison of fusion rates in patients who received both pre- and postoperative therapy versus postoperative teriparatide alone, no firm conclusions can be made. However, the cost-effectiveness of teriparatide may be increased if it can be shown that fusion rates do not significantly differ between pre- and postoperative teriparatide regimens.

\section{Study Limitations}

One limitation of this work was the lack of clinical studies evaluating fusion rates in teriparatide groups relative to those in unmedicated groups. While the results of the randomized controlled trials are promising, more studies comparing teriparatide-treated patients with unmedicated patients would reinforce the utility of postoperative teriparatide use. Another limitation of this review is the variation in the fusion grading systems used in several studies. Ohtori et al. graded fusion using the Bridwell system, whereas Cho et al. used the Ito system. Another Ohtori study did not reference a specific fusion grading system. ${ }^{3,10,12}$ The behavior of patients undergoing longterm bisphosphonate therapy is also unknown. There are also significant variations in the dosages, treatment patterns, and study designs of the various included studies. Lastly, our risk-of-bias assessment revealed that 2 of our studies did not employ randomization, 3 did not adequate- 
ly blind evaluators, and 1 study disproportionately experienced dropout in its treatment arm. $5,6,8,10,31,47$ The lack of randomization in the prospective Cho and Ohtori studies is particularly concerning, as any systematic differences between their treatment and control groups could lead to erroneous conclusions.

\section{Conclusions}

Our systematic review and meta-analysis demonstrate the benefit of bisphosphonates in accelerating fusion during a short-term monitoring period of 6 months. We also show that teriparatide is likely an optimal postoperative therapy for accelerated bone healing at long-term periods following spinal fusion in osteoporotic patients because of its rapid anabolic effects. Furthermore, while bisphosphonates have been a mainstay in osteoporosis treatment, their mechanism of action and lack of efficacy in improving long-term fusion rates may restrict their role to reducing the risk of VCFs and limiting postoperative pain and disability. Similarly, denosumab may only serve a prophylactic role, but more studies are required to evaluate its utility.

\section{References}

1. Wright NC, Looker AC, Saag KG, et al. The recent prevalence of osteoporosis and low bone mass in the United States based on bone mineral density at the femoral neck or lumbar spine. J Bone Miner Res. 2014;29(11):2520-2526.

2. Nagahama K, Kanayama M, Togawa D, et al. Does alendronate disturb the healing process of posterior lumbar interbody fusion? A prospective randomized trial. J Neurosurg Spine. 2011;14(4):500-507.

3. Cho JH, Hwang CJ, Kim H, et al. Effect of osteoporosis on the clinical and radiological outcomes following one-level posterior lumbar interbody fusion. J Orthop Sci. 2018;23(6):870-877.

4. Lane NE. Epidemiology, etiology, and diagnosis of osteoporosis. Am J Obstet Gynecol. 2006;194(2)(suppl):S3-S11.

5. Cho PG, Ji GY, Shin DA, et al. An effect comparison of teriparatide and bisphosphonate on posterior lumbar interbody fusion in patients with osteoporosis: a prospective cohort study and preliminary data. Eur Spine J. 2017;26(3):691-697.

6. Ding Q, Chen J, Fan J, et al. Effect of zoledronic acid on lumbar spinal fusion in osteoporotic patients. Eur Spine J. 2017; 26(11):2969-2977.

7. Ushirozako H, Hasegawa T, Ebata S, et al. Weekly teriparatide administration and preoperative anterior slippage of the cranial vertebra next to fusion segment $<2 \mathrm{~mm}$ promote osseous union after posterior lumbar interbody fusion. Spine (Phila Pa 1976). 2019;44(5):E288-E297.

8. Ebata S, Takahashi J, Hasegawa T, et al. Role of weekly teriparatide administration in osseous union enhancement within six months after posterior or transforaminal lumbar interbody fusion for osteoporosis-associated lumbar degenerative disorders: a multicenter, prospective randomized study. $J$ Bone Joint Surg Am. 2017;99(5):365-372.

9. Ide M, Yamada K, Kaneko K, et al. Combined teriparatide and denosumab therapy accelerates spinal fusion following posterior lumbar interbody fusion. Orthop Traumatol Surg Res. 2018;104(7):1043-1048.

10. Ohtori S, Inoue G, Orita S, et al. Teriparatide accelerates lumbar posterolateral fusion in women with postmenopausal osteoporosis: prospective study. Spine (Phila Pa 1976). 2012; 37(23):E1464-E1468.

11. Ohtori S, Inoue G, Orita S, et al. Comparison of teriparatide and bisphosphonate treatment to reduce pedicle screw loosening after lumbar spinal fusion surgery in postmenopausal women with osteoporosis from a bone quality perspective. Spine (Phila Pa 1976). 2013;38(8):E487-E492.

12. Ohtori S, Orita S, Yamauchi K, et al. More than 6 months of teriparatide treatment was more effective for bone union than shorter treatment following lumbar posterolateral fusion surgery. Asian Spine J. 2015;9(4):573-580.

13. Kim SJ, Park HS, Lee DW, Lee JW. Short-term daily teriparatide improve postoperative functional outcome and fracture healing in unstable intertrochanteric fractures. Injury. 2019; 50(7):1364-1370.

14. Rosen CJ, Bilezikian JP. Clinical review 123: Anabolic therapy for osteoporosis. J Clin Endocrinol Metab. 2001;86(3):957-964.

15. Rodan GA, Fleisch HA. Bisphosphonates: mechanisms of action. J Clin Invest. 1996;97(12):2692-2696.

16. Soldozy S, Sarathy D, Skaff A, et al. Pharmacologic considerations in patients with osteoporosis undergoing lumbar interbody fusion: a systematic review. Clin Neurol Neurosurg. 2020;196:106030.

17. Bridwell KH, Lenke LG, McEnery KW, et al. Anterior fresh frozen structural allografts in the thoracic and lumbar spine. Do they work if combined with posterior fusion and instrumentation in adult patients with kyphosis or anterior column defects? Spine (Phila Pa 1976). 1995;20(12):1410-1418.

18. Buerba RA, Sharma A, Ziino C, et al. Bisphosphonate and teriparatide use in thoracolumbar spinal fusion: a systematic review and meta-analysis of comparative studies. Spine (Phila Pa 1976). 2018;43(17):E1014-E1023.

19. Fretes N, Vellios E, Sharma A, Ajiboye RM. Radiographic and functional outcomes of bisphosphonate use in lumbar fusion: a systematic review and meta-analysis of comparative studies. Eur Spine J. 2020;29(2):272-281.

20. Park SB, Park SH, Kang YK, Chung CK. The time-dependent effect of ibandronate on bone graft remodeling in an ovariectomized rat spinal arthrodesis model. Spine J. 2014; 14(8):1748-1757.

21. Chen F, Dai Z, Kang Y, et al. Effects of zoledronic acid on bone fusion in osteoporotic patients after lumbar fusion. Osteoporos Int. 2016;27(4):1469-1476.

22. Babat LB, McLain R, Milks R, et al. The effects of the antiresorptive agents calcitonin and pamidronate on spine fusion in a rabbit model. Spine J. 2005;5(5):542-547.

23. Huang RC, Khan SN, Sandhu HS, et al. Alendronate inhibits spine fusion in a rat model. Spine (Phila Pa 1976). 2005; 30(22):2516-2522.

24. Lehman RA Jr, Kuklo TR, Freedman BA, et al. The effect of alendronate sodium on spinal fusion: a rabbit model. Spine $J$. 2004;4(1):36-43.

25. Takahata M, Ito M, Abe Y, et al. The effect of anti-resorptive therapies on bone graft healing in an ovariectomized rat spinal arthrodesis model. Bone. 2008;43(6):1057-1066.

26. Kang T, Park SY, Hong SH, et al. Bone union after spinal fusion surgery using local bone in long-term bisphosphonate users: a prospective comparative study. Arch Osteoporos. 2019;14(1):74.

27. Park YS, Kim HS, Baek SW, et al. The effect of zoledronic acid on the volume of the fusion-mass in lumbar spinal fusion. Clin Orthop Surg. 2013;5(4):292-297.

28. Lehman RA Jr, Dmitriev AE, Cardoso MJ, et al. Effect of teriparatide $[\mathrm{rhPTH}(1,34)]$ and calcitonin on intertransverse process fusion in a rabbit model. Spine (Phila Pa 1976). 2010; 35(2):146-152.

29. Ming N, Cheng JT, Rui YF, et al. Dose-dependent enhancement of spinal fusion in rats with teriparatide (PTH[1-34]). Spine (Phila Pa 1976). 2012;37(15):1275-1282.

30. O'Loughlin PF, Cunningham ME, Bukata SV, et al. Parathyroid hormone (1-34) augments spinal fusion, fusion mass volume, and fusion mass quality in a rabbit spinal fusion model. Spine (Phila Pa 1976). 2009;34(2):121-130.

31. Kim JW, Park SW, Kim YB, Ko MJ. The effect of postopera- 
tive use of teriparatide reducing screw loosening in osteoporotic patients. J Korean Neurosurg Soc. 2018;61(4):494-502.

32. Venesmaa PK, Kröger HP, Miettinen HJ, et al. Alendronate reduces periprosthetic bone loss after uncemented primary total hip arthroplasty: a prospective randomized study. $J$ Bone Miner Res. 2001;16(11):2126-2131.

33. Xue Q, Li H, Zou X, et al. Alendronate treatment improves bone-pedicle screw interface fixation in posterior lateral spine fusion: an experimental study in a porcine model. Int Orthop. 2010;34(3):447-451.

34. Black DM, Cummings SR, Karpf DB, et al. Randomised trial of effect of alendronate on risk of fracture in women with existing vertebral fractures. Lancet. 1996;348(9041):1535-1541.

35. Yishake M, Yasen M, Jiang L, et al. Effects of combined teriparatide and zoledronic acid on posterior lumbar vertebral fusion in an aged ovariectomized rat model of osteopenia. $J$ Orthop Res. 2018;36(3):937-944.

36. Deeks ED. Denosumab: a review in postmenopausal osteoporosis. Drugs Aging. 2018;35(2):163-173.

37. Hofbauer LC, Schoppet M. Clinical implications of the osteoprotegerin/RANKL/RANK system for bone and vascular diseases. JAMA. 2004;292(4):490-495.

38. Bone HG, Wagman RB, Brandi ML, et al. 10 years of denosumab treatment in postmenopausal women with osteoporosis: results from the phase 3 randomised FREEDOM trial and open-label extension. Lancet Diabetes Endocrinol. 2017; 5(7):513-523.

39. Allen MR, Burr DB. Mandible matrix necrosis in beagle dogs after 3 years of daily oral bisphosphonate treatment. $J$ Oral Maxillofac Surg. 2008;66(5):987-994.

40. Kitaguchi K, Kashii M, Ebina K, et al. Effects of weekly teriparatide administration for vertebral stability and bony union in patients with acute osteoporotic vertebral fractures. Asian Spine J. 2019;13(5):763-771.

41. Tsuchie H, Miyakoshi N, Iba K, et al. The effects of teriparatide on acceleration of bone healing following atypical femoral fracture: comparison between daily and weekly administration. Osteoporos Int. 2018;29(12):2659-2665.

42. Yamamoto J, Nakazawa D, Nishio S, et al. Impact of weekly teriparatide on the bone and mineral metabolism in hemodialysis patients with relatively low serum parathyroid hormone: a pilot study. Ther Apher Dial. 2020;24(2):146-153.

43. Almirol EA, Chi LY, Khurana B, et al. Short-term effects of teriparatide versus placebo on bone biomarkers, structure, and fracture healing in women with lower-extremity stress fractures: a pilot study. J Clin Transl Endocrinol. 2016;5:7-14.
44. Langdahl BL, Rajzbaum G, Jakob F, et al. Reduction in fracture rate and back pain and increased quality of life in postmenopausal women treated with teriparatide: 18-month data from the European Forsteo Observational Study (EFOS). Calcif Tissue Int. 2009;85(6):484-493.

45. Adogwa O, Parker SL, Shau D, et al. Cost per quality-adjusted life year gained of revision fusion for lumbar pseudoarthrosis: defining the value of surgery. J Spinal Disord Tech. 2015;28(3):101-105.

46. Pennington Z, Mehta VA, Lubelski D, et al. Quality of life and cost implications of pseudarthrosis after anterior cervical discectomy and fusion and its subsequent revision surgery. World Neurosurg. 2020;133:e592-e599.

47. Kim SM, Rhee W, Ha S, et al. Influence of alendronate and endplate degeneration to single level posterior lumbar spinal interbody fusion. Korean J Spine. 2014;11(4):221-226.

\section{Disclosures}

Dr. Wang owns stock in Innovative Surgical Devices, Medical Device Partners, Spinicity, and Kinesiometrics; is a consultant for K2M, Spineology, Stryker Spine, DePuy-Synthes Spine, and Medtronic; holds a patent with DePuy-Synthes Spine; receives royalty payments from DePuy-Synthes Spine, Children's Hospital of Los Angeles, Springer Publishing, and Quality Medical Publishing; receives grants from the Department of Defense; and is an advisory board member for Vallum. Dr. Levi receives teaching honoraria from the American Association of Neurological Surgeons and Medtronic and grant support from the Department of Defense and the National Institutes of Health (NIH-NINDS).

\section{Author Contributions}

Conception and design: Levi, Perez-Roman, Burks. Acquisition of data: Govindarajan, Diaz. Analysis and interpretation of data: Govindarajan, Diaz. Drafting the article: Govindarajan, Diaz, Perez-Roman. Critically revising the article: Perez-Roman, Burks, Wang. Reviewed submitted version of manuscript: Levi, Perez-Roman, Burks, Wang. Approved the final version of the manuscript on behalf of all authors: Levi. Statistical analysis: Govindarajan. Administrative/technical/material support: Levi. Study supervision: Levi.

\section{Correspondence}

Allan D. Levi: University of Miami Miller School of Medicine, Lois Pope Life Center, Miami, FL. alevi@med.miami.edu. 